\title{
GERENCIAMENTO DE RESULTADOS E REPUBLICAÇÃO DE DEMONSTRAÇÕES CONTÁBEIS EM EMPRESAS LISTADAS NA B3
}

\author{
Earnings management and restatement of financial results in firms \\ traded on B3
}

\begin{abstract}
Márcia Martins Mendes De Luca
E-mail: marciammdeluca@gmail.com

Pós-doutora na Grande Área de Ciências Sociais Aplicadas pela

University of Illinois at Urbana-Champaign, Estados Unidos; Doutora em Controladoria e

Contabilidade pela Universidade de São Paulo; Professora na Universidade Federal do Ceará. Endereço para contato: Avenida da Universidade, 2431, Benfica, 60020-181, Fortaleza, Ceará, Brasil.

https://orcid.org/0000-0002-9995-5637
\end{abstract}

Ana Olívia Batista Viana

E-mail: anaoliviabv@gmail.com

Graduanda em Ciências Contábeis pela Universidade Federal do Ceará.

https://orcid.org/0000-0001-7394-9733

Karen Davila Freitas de Sousa

E-mail: karenfreitas217@gmail.com

Graduanda em Ciências Contábeis pela Universidade Federal do Ceará.

https://orcid.org/0000-0003-2353-7698

Danival Sousa Cavalcante

E-mail: danival.cavalcante@ufca.edu.br

Mestre em Administração e Controladoria pela Universidade Federal do Ceará; Doutorando em

Administração e Controladoria na Universidade Federal do Ceará; Professor na Universidade

Federal do Cariri.

https://orcid.org/0000-0002-7474-1480

Vanessa Ingrid da Costa Cardoso

E-mail: nessaingrid@gmail.com

Mestra em Administração e Controladoria pela Universidade Federal do Ceará; Doutoranda em Administração e Controladoria na Universidade Federal do Ceará; Servidora técnico-administrativa em Educação na Universidade da Integração Internacional da Lusofonia Afro-Brasileira.

https://orcid.org/0000-0003-4174-9686

Artigo recebido em 30 de dezembro de 2019. Aceito em 17 de junho de 2020. 


\section{Resumo}

As informações divulgadas nas demonstrações contábeis impactam diretamente no processo decisório dos stakeholders. Nesse contexto, busca-se confirmar se as empresas que gerenciam resultados têm maior propensão a republicar suas demonstrações contábeis. O objetivo deste estudo é investigar as relações entre o gerenciamento de resultados e a republicação das demonstrações contábeis nas companhias listadas na B3-Brasil, Bolsa, Balcão. A amostra da pesquisa reúne 154 empresas e 201 casos de republicação de demonstrações contábeis entre 2011 e 2017. Para análise dos dados, foram aplicadas técnicas de análise de conteúdo, estatística descritiva, análise de correlação e regressão logística. Os resultados apontam para uma relação entre a republicação de demonstrações contábeis e a prática de gerenciamento de resultados por accruals discricionários, não se rejeitando a hipótese do estudo. Verificouse, ainda, uma elevada proporção de republicações voluntárias, sugerindo que as empresas são propícias a adotarem esse procedimento com a finalidade de prover para os usuários uma maior qualidade das informações contábeis.

Palavras-chave: Gerenciamento de resultados. Republicação de demonstrações contábeis. Qualidade da informação.

\section{Abstract}

The information presented in financial statements directly impacts the stakeholders' decisionmaking. In this context, we intended to verify the relationship between earnings management and the restatements of financial results. In this study, we evaluated whether firms engaging in earnings management are more prone to restate their financial results, based on a sample of 154 firms traded on B3 (Brazilian Stock Exchange) and 201 restatements, covering the period 2011-2017. The collected data was submitted to content analysis, descriptive statistics, correlation analysis and logistic regression. Our results point to a positive association between restatement of financial results and earnings management by discretionary accruals; in other words, the study hypothesis could not be rejected. Interestingly, a considerable part of the restatements was voluntary, suggesting that many firms wish to provide information users with better earnings quality.

Keywords: Earnings management. Restatement of financial results. Earnings quality.

\section{INTRODUÇÃO}

Nos últimos anos tem crescido o interesse de pesquisadores em explorar e compreender os motivos e comportamentos que levam as empresas a fazerem a republicação voluntária de suas demonstrações contábeis (Alali \& Wang, 2017; Liu \& Yu, 2018; Mao, 2018; Rahmanian, Rahmani, \& Jafari, 2016). Do mesmo modo, emergiu também o interesse por investigar o possível efeito das práticas de gerenciamento de resultados na republicação das demonstrações contábeis (Cunha, Fernandes, \& Magro, 2017; Marques, Amaral, Souza, Santos, \& Belo, 2017; Mortazavi \& Salehi, 2017).

A republicação de demonstrações contábeis pode ser definida como a revisão ou atualização de demonstrações contábeis previamente emitidas pela empresa. Entre os objetivos da republicação de demonstrações contábeis, destaca-se a necessidade de dar ciência de erros cometidos (falhas, omissões ou fraude) em demonstrações anteriormente 
apresentadas, divulgando, assim, os documentos devidamente corrigidos (He \& Chiang, 2013; Lin, Lee, Chen, \& Yur-Austin, 2015). E, entre as várias explicações para a republicação, destacam-se aquelas relacionadas às práticas de gerenciamento de resultados (Ettredge, Scholz, Smith, \& Sun, 2010; Linn \& Diehl, 2005).

A informação contábil sofre influência de diversos aspectos, como, por exemplo, a definição de critérios de reconhecimento, mensuração e evidenciação pelos gestores, também conhecidos por discricionariedade de escolhas contábeis, podendo ter o intuito de influenciar a interpretação dos stakeholders acerca do desempenho da firma e em suas decisões de investimentos (Healy \& Wahlen, 1999). Segundo Healey e Wahlen (1999), os gestores utilizam também esse julgamento para estruturar e alterar uma operação com o objetivo de influenciar os resultados contratuais que dependem dos números contábeis. Esses cenários caracterizam o gerenciamento de resultados.

Cabe destacar que o gerenciamento de resultados ocorre em razão da discricionariedade dos gestores no processo de elaboração dos relatórios contábeis e, embora seja considerada uma representação distorcida e intencional do desempenho econômico da firma, é realizado a partir das alternativas possibilitadas pelas normas contábeis, não se confundindo, portanto, como fraude ou outro ato doloso (Costa, De Luca, Góis, \& Lima, 2018; Marçal \& Macedo, 2019, Mulford \& Comiskey, 2002; Scott, 2003; Silva A., Silva C., Sanconvschi, \& Borba, 2018).

O gerenciamento de resultados vem sendo estudado há longos anos por diversos pesquisadores, que buscam inúmeras relações dessa prática com diferentes variáveis no âmbito corporativo empresarial (Healy \& Wahlen, 1999; Marques et al., 2017; Piccoli, Souza, \& Silva, 2014; Teoh, Welch, \&Wong, 1998).

Embora a prática de gerenciamento de resultados possa ser realizada dentro dos limites aceitos pelos princípios e práticas contábeis e com amparo da auditoria externa, que verifica a conformidade das informações com o que é permitido pelas normas contábeis (Teoh et al., 1998), a organização, ao apresentar resultados manipulados, deixa de refletir a representação fidedigna de sua situação econômico-financeira e patrimonial (Healy, Hutton, \& Palepu, 1999; Piccoli et al., 2014).

Nesse contexto, cabe destacar que ainda são consideradas incipientes as pesquisas que abordam o relacionamento e a influência do gerenciamento de resultados sobre a republicação, espontânea ou obrigatória, das demonstrações contábeis, principalmente no âmbito corporativo brasileiro (Cunha et al., 2017; Marques et al., 2017).

A partir desse amplo campo de pesquisa disponível, o presente estudo lança o seguinte questionamento: As práticas de gerenciamento de resultados se relacionam com a ocorrência de republicação das demonstrações contábeis em companhias listadas na B3Brasil, Bolsa, Balcão? 
Com o interesse de contribuir para o avanço do estudo científico dos temas abordados, e para buscar respostas para o questionamento exposto, este estudo tem por objetivo investigar as relações entre as práticas de gerenciamento de resultados e a republicação das demonstrações contábeis em companhias listadas na B3 durante o período de 2011 a 2017. Pretende-se, ainda, verificar quais são as variáveis características das empresas (incluindo aquelas relacionadas ao gerenciamento de resultados) que apresentam probabilidades significantes que as tornam propensas a republicarem suas demonstrações contábeis.

Ressalta-se a relevância deste estudo para a ampliação da literatura que aborda a relação entre a republicação das demonstrações contábeis e o gerenciamento de resultados, bem como sua contribuição para realçar, complementar ou questionar achados de estudos anteriores (Cunha et al., 2017; Marques et al., 2017), promovendo a evolução do conhecimento científico sobre os temas. Destaca-se ainda a contribuição do estudo para o mercado de capitais, na medida em que a crescente republicação das demonstrações contábeis (Mao, 2018) constitui um dos principais temas no debate sobre a qualidade das informações contábeis divulgadas (Alali \& Wang, 2017; Marçal \& Macedo, 2019; Mortazavi \& Salehi, 2017; Rahmanian et al., 2016).

Cabe destacar que a literatura aponta que a adoção das International Financial Reporting Standards (IFRS) tem efeito positivo na qualidade das demonstrações contábeis, reduzindo, assim, a probabilidade de republicação (Linhares, Costa, \& Beiruth, 2018; Oliveira \& Lemes, 2011). Dessa forma, este estudo diferencia-se ao considerar apenas as informações contábeis das empresas que seguem o padrão contábil internacional para reconhecimento, mensuração e evidenciação das demonstrações contábeis, visto que o início da obrigatoriedade no Brasil ocorreu em 2010.

\section{REVISÃO DA LITERATURA}

Esta seção apresenta a revisão da literatura e os estudos empíricos anteriores sobre os temas centrais da presente pesquisa: gerenciamento de resultados e republicação das demonstrações contábeis.

\subsection{GERENCIAMENTO DE RESULTADOS E REPUBLICAÇÃO DAS DEMONSTRAÇÕES CONTÁBEIS}

A Teoria da Agência estabelece que, ao buscar a maximização de suas utilidades, os gestores nem sempre desempenham suas funções estritamente voltados para atingir os interesses da firma (proprietários), tomando, muitas vezes, decisões questionáveis do ponto de vista 
corporativo (Jensen \& Meckling, 1976). Entre essas decisões, destacam-se aquelas relacionadas às práticas de gerenciamento de resultados, realizadas a partir das escolhas permitidas pelas normas contábeis, em que são verificadas alterações propositadamente introduzidas em relatórios financeiros de empresas com a finalidade de modificar a informação contábil e apresentar resultados que beneficiem suas relações contratuais (Healy \& Wahlen, 1999).

Marques et al. (2017) também relacionam o gerenciamento de resultados com a realização de escolhas contábeis e operacionais com o objetivo de alcançar interesses específicos dos gestores ou da própria firma. Os citados autores advertem que, ainda que a princípio a prática seja vista como oportunística, especialmente por investidores que precisam de informações de qualidade para subsidiar suas decisões, o gerenciamento de resultados praticado pelas organizações nem sempre é classificado como fraude. Embora a prática do gerenciamento de resultados gere algum tipo de informação manipulada (Piccoli et al., 2014), Teoh et al. (1998) argumentam que a prática pode ser adotada dentro de limites permitidos pelos princípios e práticas contábeis.

Dessa forma, apesar da possibilidade de ser praticado para apresentar informações mais alinhadas com os objetivos da gestão, o gerenciamento de resultados acarreta a divulgação de uma situação não fidedigna da empresa, podendo impactar negativamente aqueles que fazem uso de tais informações no processo decisório (Joia \& Nakao, 2014).

Os gestores possuem diversas motivações para realizar o gerenciamento de resultados, para atingir tanto objetivos próprios quanto da própria entidade (Marques et al., 2017). A alteração do montante do lucro é um dos clássicos exemplos, em que seu aumento visa melhorar a remuneração dos gestores, e a sua diminuição tem por finalidade a redução de impostos (Murcia \& Wuerges, 2011). Consoni, Colauto, e Lima (2017) afirmam que o gerenciamento de resultados ocorre em razão da inexistência de uma medida precisa acerca do lucro líquido. Joia e Nakao (2014) destacam a prática de gerenciamento da diminuição da volatilidade dos resultados e a relutância das empresas em divulgarem suas perdas.

Entre os diversos tipos possíveis de gerenciamento de resultados, os dois mais recorrentes e estudados são a manipulação por accruals discricionários e a manipulação das atividades operacionais (Abad, Cutillas-Gomariz, Sánchez-Ballesta, \& Yagüe, 2018; Gao, J., Gao, B., \& Wang, 2017; Mao, 2018; Mcvay, 2006). Na manipulação por accruals discricionários ou acumulações, o gestor pode modificar a informação contábil com o reconhecimento do resultado pelo regime da competência, por meio de diversos aspectos relativos às escolhas contábeis e políticas de gestão financeira da entidade (Barros, Menezes, Colauto, \& Teodoro, 2014). Os accruals discricionários modificam o lucro líquido, porém não refletem no fluxo de caixa da empresa (Dechow \& Dichev, 2002).

A manipulação das atividades operacionais ou reais consiste em modificações realizadas em relatórios empresariais com o objetivo de motivar os usuários a acreditarem 
no cumprimento de determinadas metas propostas para o período, sendo ainda considerada um mecanismo utilizado para evitar a divulgação de perdas, além de afetar o fluxo de caixa (Roychowdhury, 2006).

Considerando-se que o gerenciamento de resultados tem reflexo direto na qualidade da informação divulgada para os stakeholders, frisa-se aqui a relevância de um dos construtos deste estudo: a republicação das demonstrações contábeis. As demonstrações contábeis constituem uma das principais fontes de informações para subsidiarem as decisões dos investidores, credores e demais usuários das informações contábeis (Chen, Goo, \& Shen, 2014).

Segundo He e Chiang (2013), a republicação consiste na reelaboração e divulgação das informações contábeis quando são identificados erros ou omissões materiais após a divulgação das demonstrações contábeis. Conforme lecionam Lin et al. (2015), a republicação é uma revisão formal das demonstrações financeiras previamente emitidas em decorrência de alterações contábeis ou de violação de princípios contábeis.

Albring, Huang, Pereira, e Xu (2013) e Wiedman e Hendricks (2013) explicam que a republicação das demonstrações geralmente pode ser voluntária, ou ser recomendada pelos auditores ou por um órgão regulador. Quando o órgão regulador competente identifica uma inconsistência material (intencional ou não), poderá, "de ofício" (também chamada de republicação obrigatória), solicitar que a companhia refaça e republique as demonstrações, sem prejuízo da responsabilização por danos cíveis ou criminais cabíveis (Dantas, Chaves, Silva, \& Carvalho, 2011). No entanto, caso a companhia ou os auditores identifiquem erro ou falha que altere a interpretação dos dados divulgados, poderá, espontaneamente, proceder à alteração (republicação voluntária). No caso do Brasil, a maioria das republicações das demonstrações é espontânea (voluntária), e geralmente tem por finalidade corrigir dados qualitativos (Marques et al., 2017).

Cunha et al. (2017) e Teixeira, Politelo, e Klann (2013) advertem que existe diferença entre a republicação e o refazimento das demonstrações contábeis, já que a republicação corrige informações enviesadas, confusas ou incompletas, sem afetar a situação patrimonial, enquanto o refazimento inclui registros não realizados (provisões, erros em estimativas contábeis, classificação incorreta de contas), que alteram a situação patrimonial da empresa. O refazimento geralmente é acompanhado da republicação, que ocorre em razão da exigência de órgão regulador (Teixeira et al., 2013). Neste estudo, utiliza-se o termo republicação para quaisquer das justificativas de apresentação de demonstrações contábeis alteradas.

As republicações estão associadas a irregularidades contábeis e consomem alto volume de recursos financeiros, em decorrência dos riscos de litígio, reputação e expropriação (Elayan, Li, \& Meyer, 2008). Entretanto, não se restringem a irregularidades, pois podem ocorrer inclusive por motivações qualitativas, para correção de dados relativos às notas explicativas, relatórios de administração e outros (Helou \& Pereira, 2010). 
Segundo Bills, Swanquist e Whited (2016), a republicação das demonstrações contábeis constitui um indicador da qualidade das demonstrações e da qualidade da auditoria. Assim, a republicação pode ser um indicativo da baixa qualidade das demonstrações anteriormente publicadas, bem como pode sugerir uma inferior qualidade da auditoria, já que esta não foi capaz de detectar, de forma oportuna, os erros e/ou inconsistências (Chiudini, Cunha, \& Marques, 2018). Marques et al. (2017) destacam que ao corrigir o reconhecimento, mensuração elou divulgação de dados para alterar a avaliação e interpretação dos usuários externos, a republicação de demonstrações contábeis reduz o risco de seleção adversa por parte desse segmento.

No que tange às possíveis reações do mercado quanto às republicações, de acordo com Bischoff, Finley, e Leblanc (2008), o mercado de ações tende a reagir negativamente à notícia de refazimento, pois isso dá aos investidores a percepção de que a gestão vem tentando fraudar as informações intencionalmente ou que é incapaz de elaborar as demonstrações com qualidade. Entretanto, na visão de Helou e Pereira (2010), a reação do mercado à republicação das demonstrações pode ser positiva, na medida em que sinaliza aos stakeholders que a organização busca apresentar informações mais fidedignas.

Dadas as características desse tipo de evento e a relevância para o mercado, a identificação de distorções relevantes nas demonstrações financeiras e a determinação de sua republicação têm sido objeto de pesquisas empíricas que procuram compreender o contexto em que aconteceram e as consequências econômicas de sua ocorrência (Palmrose, Richardson, \& Scholz, 2004; Richardson, Tuna, \& Wu, 2002). Assim, entre os possíveis motivos para a republicação das demonstrações contábeis, Bischoff et al. (2008) destacam o reconhecimento indevido de contas de resultado, a forma de reconhecimento das remunerações baseadas em ações e os erros de classificação de fatos em contas contábeis.

No Brasil, o tema republicação de demonstrações contábeis ainda carece de mais estudos e aprofundamentos para ampliação do campo de pesquisa, ao contrário do que ocorre no cenário internacional (Alali \& Wang, 2017; Liu \& Yu, 2018; Mao, 2018; Mortazavi \& Salehi, 2017; Rahmanian et al., 2016). Marques et al. (2017) afirmam que, no contexto brasileiro, há escassez de estudos sobre republicação, em sua maioria porque as informações sobre republicação disponibilizadas nos bancos de dados não expõem detalhes que viabilizem tal levantamento.

\subsection{ESTUDOS EMPÍRICOS ANTERIORES}

Vários estudos abordaram o comportamento do mercado com relação à republicação das demonstrações contábeis. Alguns demostraram haver uma reação negativa do mercado, representada por queda nos preços das ações (Richardson et al., 2002), especialmente quando a republicação envolve fraudes, afeta mais contas contábeis e altera as principais receitas (Palmrose et al., 2004). Chen, Elder, e Hung (2014) expõem que o mercado reage 
negativamente às republicações, fazendo ainda com que informações posteriormente divulgadas percam a credibilidade.

Contudo, no cenário brasileiro, Helou e Pereira (2010) não encontraram reação positiva nem negativa do mercado às republicações de informações contábeis, pois não verificaram retornos anormais acumulados significativamente diferentes de zero. Marques et al. (2017) sinalizam que a reação ao mercado pode ser positiva quando a republicação é capaz de reduzir o risco de seleção adversa.

Conforme Helou e Pereira (2010), as reações do mercado brasileiro às republicações podem diferir de outros países, provavelmente pelos distintos motivos que levam as empresas brasileiras e estrangeiras a republicarem. Para os autores, o efeito neutro, em geral apresentado nas pesquisas com empresas no Brasil, pode ser justificado pela alta frequência de correções de erros que raramente afetam o resultado, limitando-se aos ajustes de comentários sobre desempenho, correção de notas explicativas e de informações no relatório da administração.

Segal, Callen, e Livnat (2006) compararam a reação do mercado às republicações causadas por mudanças nos princípios contábeis com aquelas devidas a erros, e observaram uma reação negativa às republicações derivadas de erros, inferindo que as reações do mercado a anúncios de republicação, que derivam um aumento de receita por mudanças nos princípios contábeis, não são estatisticamente diferentes de zero. Os autores apontaram basicamente três razões: problemas no sistema contábil que podem ser consequências de grandes problemas gerenciais e operacionais; diminuição das expectativas de fluxos de caixa futuros; e manipulação dos resultados na tentativa de encobrir queda dos lucros.

Murcia, Borba, e Amaral (2005) analisaram as determinações da CVM para republicação de demonstrações contábeis no período de 2001 a 2004, e observaram que entre as diferentes causas, destacaram-se aquelas relacionadas aos instrumentos financeiros e aos ativos e passivos contingentes, sendo que em quase todas o parecer do auditor externo continha parágrafo de ressalva.

No contexto das 500 maiores empresas da Austrália, Ahmed e Goodwin (2007) analisaram 150 republicações, encontrando diminuição no lucro em cerca de $49 \%$ delas. Os autores destacaram três razões nas republicações analisadas: mudança nas políticas contábeis (49\%); revisão de estimativas (40\%); e erros "não identificados" (11\%).

Dantas et al. (2011) investigaram os casos de republicação de demonstrações determinados pela CVM no período de 2001 a 2009, e encontraram como principais motivos o reconhecimento e a mensuração de ativos e passivos $(45,4 \%)$, a deficiência no processo de divulgação (disclosure) das notas explicativas (39\%); e o reconhecimento e a mensuração de receitas e despesas (7,8\%). Segundo Collins, Masli, Reitenga, e Sanchez (2009), essas motivações de republicação obrigatória corroboram estudos estrangeiros, já que nos últimos 
anos as falhas nos processos de mensuração de itens patrimoniais e de resultados respondem por mais de $50 \%$ dos motivos.

Ao analisar 5.608 demonstrações de empresas listadas na BM\&FBovespa referentes ao período de 1997 a 2012, Marques, Aires, Cerqueira, Silva, e Amaral (2016) constataram que, em média, $25 \%$ foram republicadas, $17 \%$ são do tipo obrigatório e apenas $8,4 \%$ se referem a alterações quantitativas. Os autores verificaram que houve um aumento das republicações, o que acompanhou o crescimento da quantidade de empresas listadas na BM\&FBovespa; no entanto, $77,1 \%$ desse total decorreram de alterações de dados qualitativos.

Entre os problemas registrados para as 11.868 correções de demonstrações contábeis ocorridas do período pré-SOX para o pós-SOX, de 2000 a 2011, Lin et al. (2015) constataram que a maioria foi falha na aplicação de regras contábeis, e que os problemas de fraude foram associados com mais frequência ao reconhecimento de receita.

Com base nesses indicativos de explicações (motivos) para a republicação de demonstrações contábeis, pode-se sugerir um relacionamento entre os temas republicação de demonstrações contábeis e gerenciamento de resultados. Linn e Diehl (2005) afirmam que o gerenciamento de resultados é, sem dúvida, uma das causas originais das republicações. Ettredge et al. (2010) encontraram evidências de que até mesmo as reformulações não intencionais de violação dos Generally Accepted Accounting Principles (GAAP) podem ser vinculadas ao gerenciamento de resultados, uma prática que diminui a qualidade dos relatórios financeiros.

Richardson et al. (2002) verificaram que as empresas que republicavam os lucros possuíam uma expectativa de maior crescimento da geração de caixa e maiores níveis de dívidas. Adicionalmente, evidenciaram que essas empresas tentavam manter uma sequência de crescimento dos lucros, sugerindo que a pressão do mercado de capitais é um fator motivador para a adoção de políticas contábeis agressivas. O estudo de Richardson et al. (2002) aponta que as pressões do mercado de capitais influenciam as empresas a adotarem políticas contábeis agressivas e que as informações contidas nos accruals podem ser relevantes para antecipar o gerenciamento de resultados nas empresas que republicaram suas demonstrações financeiras.

Baptista (2008) analisou se as demonstrações financeiras de empresas que foram objeto de republicação possuem caráter informativo sobre a prática do gerenciamento de resultados, e verificou que as práticas contábeis registradas nos ofícios sugerem que as empresas gerenciaram seus resultados a fim de alterar a expectativa dos usuários com relação ao futuro da companhia.

Cunha et al. (2017) verificaram a influência do refazimento das demonstrações contábeis no gerenciamento de resultados nas empresas listadas na BM\&FBovespa, durante os exercícios do período de 1995 a 2012, e não encontraram diferenças significativas, concluindo que não houve gerenciamento de resultados superior ou inferior decorrente do refazimento 
para essas empresas. Por outro lado, ao comparar as empresas com refazimento em relação às que não foram obrigadas à mesma providência, observou-se que o refazimento influencia o gerenciamento de resultados negativo.

Marques et al. (2017) analisaram a relação entre as hipóteses de gerenciamento de resultados e as republicações das demonstrações contábeis de 344 empresas listadas na BM\&FBovespa, no período de 1998 a 2014, e observaram que o tamanho, o crescimento dos ativos, ser auditada por uma Big Four e a adoção das IFRS tiveram efeito positivo e estatisticamente significativo sobre a probabilidade de republicação das demonstrações.

Portanto, com base na litera tura que ressalta a relevância da divulgação de informações contábeis que representem fidedignamente a situação econômico-financeira da empresa (Healy \& Wahlen, 1999; Piccoli et al., 2014), a fim de minimizar o efeito de informações manipuladas no processo decisório dos stakeholders (Ettredge et al., 2010; Joia \& Nakao, 2014; Richardson et al., 2002), e dos estudos empíricos anteriores aqui apresentados sobre os temas gerenciamento de resultados e republicação das demonstrações contábeis, tem-se a seguinte hipótese do estudo: as empresas que gerenciam resultados têm maior propensão a republicarem suas demonstrações contábeis.

Cabe destacar que todas as informações contábeis das empresas analisadas, para fins de verificar a hipótese de pesquisa, seguem as normas internacionais de Contabilidade, cujo início da obrigatoriedade no Brasil ocorreu em 2010, reforçando este estudo, haja vista a literatura que destaca a relevância da adoção das IFRS para a qualidade das demonstrações contábeis (Linhares et al., 2018; Oliveira \& Lemes, 2011).

\section{METODOLOGIA}

Frente ao escopo do estudo, a caracterização metodológica segue de acordo com as classificações apresentadas por Sampieri, Collado, e Lúcio (2013), que delineiam as pesquisas em razão do objetivo, procedimentos e abordagem do problema. Dessa forma, em consonância com os objetivos da pesquisa, pode-se classificá-la como descritiva, haja vista que procura descrever o processo de republicação de demonstrações contábeis, além de verificar sua relação com as características empresariais. Além disso, o estudo tem naturezas qualitativa e quantitativa, sendo esta última a preponderante.

Foi realizada a análise de conteúdo das demonstrações republicadas para identificação dos motivos das reapresentações. Adicionalmente, procedeu-se à análise dos dados com uso de técnicas estatísticas, com o intuito de se verificarem possíveis relações entre a republicação das demonstrações e a prática de gerenciamento de resultados. Para obtenção dos dados da pesquisa, foram coletadas informações secundárias de companhias de capital aberto listadas na B3. 
Os dados relativos à republicação das demonstrações contábeis foram obtidos no site da B3. Vale salientar que, a priori, pesquisou-se a listagem de empresas disponibilizada no site da CVM, a qual inclui aquelas que receberam da CVM a determinação para refazimento e/ou republicação de suas demonstrações financeiras e informações trimestrais obrigatórias. Os dados econômico-financeiros das empresas para mensuração das variáveis de gerenciamento de resultados foram obtidos dos bancos de dados Compustat e Wordscope.

A amostra compreende 154 empresas e 814 observações referentes ao período de 2011 a 2017. Foram constatadas 201 ocorrências de republicação de demonstrações contábeis. A opção pelo período de 2011 a 2017 se deve ao fato de o estudo adotar o modelo Jones Modificado, proposto por Dechow, Sloan, e Sweeny (1995), em que são utilizados dados de ativo defasado, requerendo, portanto, dados desde o ano de 2010, o qual corresponde ao início da adoção obrigatória das IFRS pelas empresas no Brasil, até 2017, período mais recente das demonstrações contábeis divulgadas até a data da conclusão desta pesquisa. Assim, analisase a republicação de demonstrações contábeis desde o início da obrigatoriedade da adoção das normas internacionais de contabilidade (IFRS) pelas companhias abertas listadas na B3.

Para alcançar os objetivos propostos na pesquisa, efetuou-se, além da análise de conteúdo, estatística descritiva, análise de correlação e análise de regressão logística, sendo esta última no intuito de investigar a prática de gerenciamento de resultados com relação à propensão das empresas a republicarem suas demonstrações contábeis. Optou-se pela regressão logística por se tratar de técnica estatística que busca a relação de dependência entre variáveis, sendo que a variável dependente é dicotômica. Desse modo, a Equação 1 representa o modelo que procura alcançar o objetivo de pesquisa e testar a hipótese de estudo:

$$
P R(R E P U B=1)=f\left(\beta_{0}+\beta_{1} A D A C C_{i t}+\beta_{2} R E A L_{i t}+\beta_{n} \Sigma(\text { Controles })_{i t}\right)
$$

A variável dependente é a republicação das demonstrações contábeis (REPUB), assumindo o valor 1 quando a empresa realiza republicação, e o valor nulo no caso contrário. Como variáveis independentes, tem-se o gerenciamento de resultados por meio da manipulação por accruals discricionários, modelo Jones Modificado proposto por Dechow et al. (1995) e por meio da manipulação das atividades operacionais, ou manipulação por atividades reais (Roychowdhury, 2006). O gerenciamento de resultados (GR) foi operacionalizado da seguinte forma: accruals discricionários (ADACC), representados pelo valor absoluto dos resíduos, conforme Dechow et al;; e manipulação das atividades operacionais (REAL), representada pela soma dos resíduos padronizados de manipulação de vendas (SMAN), redução de despesas discricionárias (DIXEP) e superprodução (PROD), conforme Cohen, Dey, e Lys (2008) e Roychowdhury (2006). 
Por sua vez, são consideradas as seguintes variáveis de controle, também adotadas em estudos anteriores: tamanho da empresa (TAM), calculado pelo logaritmo natural do Ativo (Abad et al., 2018; Grecco, 2013; Soares, Motoki, \& Monte-Mor, 2018); rentabilidade (REN), obtida pela razão entre o lucro antes de itens extraordinários e o Patrimônio Líquido (Abad et al., 2018; Barros et al., 2014; Cunha et al., 2017; Soares et al., 2018); endividamento (END), determinado pela razão entre as dívidas totais e o Ativo (Cunha et al., 2017; Grecco, 2013; Soares et al., 2018); crescimento de vendas (CRES), representado pela variação proporcional da receita de vendas (Barros et al., 2014; Cunha et al., 2017; Góis \& Soares, 2019); e (v) market-to-book (MTB), representado pela razão entre valor de mercado e Patrimônio Líquido (Ahmed \& Goodwin, 2007; Góis \& Soares, 2019).

No processo de aplicação das técnicas propostas, utilizaram-se as ferramentas de análise estatística do software Stata.

\section{APRESENTAÇÃO E ANÁLISE DOS RESULTADOS}

A análise de conteúdo das demonstrações contábeis das empresas da amostra possibilitou a identificação de 201 republicações e dos seus motivos, bem como daquelas que resultaram em alteração nos resultados das companhias. Vale salientar que houve casos em que as empresas republicaram mais de uma vez durante o período sob análise. A Figura l apresenta as republicações observadas quanto à frequência de exercícios contábeis em que ocorreram.

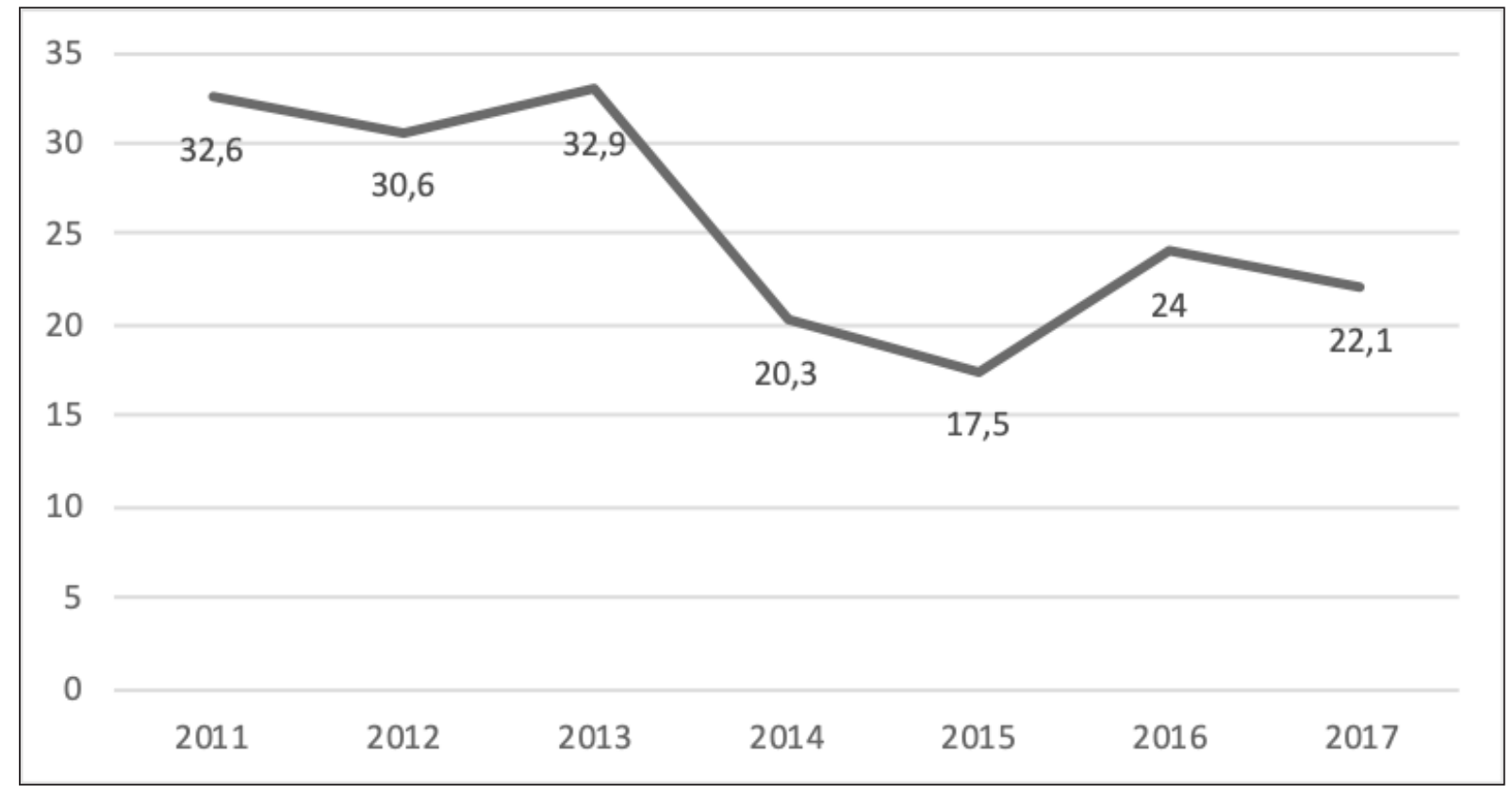

Figura 1. Frequência de republicações de demonstrações contábeis no período de 2011 a 2017. 
De um total de 201 republicações durante o período sob análise, os três primeiros exercícios apresentaram maior proporção, provavelmente em razão do fato de serem os primeiros anos de publicação dos demonstrativos em IFRS. Observa-se, ainda, uma redução de republicação ao longo dos anos, sendo 2015 o exercício que registrou a menor proporção $(17,5 \%)$.

Observou-se que são diversos os motivos para republicação. Inicialmente, as republicações foram quantificadas quanto à forma, entre espontânea (voluntária) e por exigência (obrigatória), conforme apontado pela literatura (Albring et al., 2013; Marques et al., 2017; Wiedman \& Hendricks, 2013), revelando-se que aproximadamente $90 \%$ foram espontâneas e $10 \%$ por exigência.

Das republicações feitas por exigência, os principais motivos foram ajustes em pareceres e ajustes de datas ou inclusão/ajuste de informações, não sendo identificados casos de alteração de valores, representando de forma combinada $70 \%$ dos casos. Apenas uma das republicações foi exigida pela B3 e não pela CVM, para ajuste de dados qualitativos. Tal achado divergiu das observações de Collins et al. (2009), já que, segundo esses autores, $50 \%$ dos casos de exigência de republicação ocorreram por problemas de mensuração de itens patrimoniais e de resultados.

Adicionalmente, verificou-se que as republicações advêm principalmente por motivo de ajustes nas evidenciações, especialmente nas notas explicativas. Tal observação coaduna com o mapeamento realizado por Dantas et al. (2011), cujo estudo revelou que a necessidade de republicação das demonstrações ocorre principalmente em razão da deficiência ou ausência de disclosure em notas explicativas, além de impropriedades no reconhecimento el ou mensuração de ativos e passivos.

Por outro lado, os resultados encontrados neste estudo vão de encontro aos principais motivos para o refazimento e a republicação das demonstrações identificados por Chiudini et al. (2018), a saber: reconhecimento indevido de receitas e despesas, reconhecimento das remunerações baseadas em ações e erros de classificação de contas contábeis. Também divergem dos achados de Murcia et al. (2005), cuja pesquisa gerou resultados que levam à conclusão de que as principais causas para a determinação de refazimento das informações contábeis foram os instrumentos financeiros e os ativos e passivos contingentes.

Assim como destacado por Murcia e Carvalho (2007), não é somente por motivos de fraude que a CVM exige a republicação de demonstrações, mas também em razão da insuficiência de informação relevante. Vale salientar que a CVM vem envidando esforços visando ao aumento da qualidade da informação disponibilizada por meio de demonstrações financeiras (Souza, Peters, Silva, \& Antunes, 2018).

Diante dos dados introdutórios, parte-se para a análise descritiva das variáveis consideradas na pesquisa. Ressalta-se que foi realizada a técnica de winsorização para 
tratamento dos outliers das variáveis utilizadas na pesquisa, considerando o primeiro e o nonagésimo percentis. A Tabela 1 apresenta a estatística descritiva das variáveis:

Tabela 1

Estatística descritiva

\begin{tabular}{|c|c|c|c|c|c|c|c|}
\hline Variável & Republicação & $\begin{array}{c}\text { N. de } \\
\text { observações }\end{array}$ & Média & $\begin{array}{l}\text { Desvio-pa- } \\
\text { drão }\end{array}$ & Mínimo & Máximo & Teste $†$ \\
\hline \multirow[t]{3}{*}{ ADACC } & Sim & 201 & 0,063 & 0,076 & 0,000 & 0,596 & 0,772 \\
\hline & Não & 613 & 0,070 & 0,120 & 0,000 & 1,246 & \\
\hline & Total & 814 & 0,068 & 0,111 & 0,000 & 1,246 & \\
\hline \multirow[t]{3}{*}{ REAL } & Sim & 201 & $-0,013$ & 0,344 & $-0,958$ & 3,209 & $-2,604^{(* * *)}$ \\
\hline & Não & 613 & $-0,069$ & 0,239 & $-1,157$ & 0,981 & \\
\hline & Total & 814 & $-0,055$ & 0,270 & $-1,157$ & 3,209 & \\
\hline \multirow[t]{3}{*}{ TAM } & Sim & 201 & 8,167 & 1,757 & 2,001 & 12,495 & $-2,577^{(* * *)}$ \\
\hline & Não & 613 & 7,772 & 1,925 & 1,787 & 13,599 & \\
\hline & Total & 814 & 7,869 & 1,891 & 1,787 & 13,599 & \\
\hline \multirow[t]{3}{*}{ REN } & Sim & 201 & 0,013 & 0,483 & $-3,086$ & 1,423 & $-0,4024$ \\
\hline & Não & 613 & 0,034 & 0,679 & $-6,560$ & 2,470 & \\
\hline & Total & 814 & 0,029 & 0,636 & $-6,560$ & 2,470 & \\
\hline \multirow[t]{3}{*}{ END } & Sim & 201 & 0,381 & 0,415 & 0,000 & 5,079 & 0,365 \\
\hline & Não & 613 & 0,400 & 0,663 & 0,000 & 9,352 & \\
\hline & Total & 814 & 0,395 & 0,611 & 0,000 & 9,352 & \\
\hline \multirow[t]{3}{*}{ CRES } & $\operatorname{Sim}$ & 201 & 0,123 & 0,441 & $-0,997$ & 4,042 & $-2,072^{(* *)}$ \\
\hline & Não & 613 & 0,066 & 0,294 & $-0,847$ & 3,179 & \\
\hline & Total & 814 & 0,080 & 0,337 & $-0,997$ & 4,042 & \\
\hline \multirow[t]{3}{*}{ MTB } & Sim & 201 & 1,020 & 14,263 & $-6,399$ & 202,020 & 0,554 \\
\hline & Não & 613 & 2,002 & 23,760 & -107,702 & 406,386 & \\
\hline & Total & 814 & 1,760 & 21,799 & -107,702 & 406,386 & \\
\hline
\end{tabular}

Nota. $\left({ }^{* *}\right),\left({ }^{* * *}\right)=$ significância aos níveis de $5 \%$ e $1 \%$, respectivamente; ADACC = accruals discricionários; REAL = manipulação das atividades operacionais; $T A M=$ tamanho; $R E N$ = rentabilidade; $E N D$ = endividamento; CRES = crescimento de vendas; MTB = market-to-book

De acordo com a Tabela l, entre as empresas que republicaram seus demonstrativos, - valor médio de gerenciamento de resultados por maio da manipulação por accruals discricionários (ADACC) é positiva e superior ao gerenciamento pela manipulação por atividades operacionais (REAL), que é negativa. Além disso, as empresas que republicaram seus demonstrativos apresentam médias superiores em relação às empresas que não republicaram suas demonstrações, exceto para as variáveis manipulação por accruals discricionários (ADACC) e rentabilidade (REN). Observa-se ainda, a partir do teste $t$, que apenas para manipulação por atividades operacionais (REAL), tamanho (TAM) e crescimento de vendas (CRES) existe uma diferença estatisticamente significante entre as empresas que republicam ou não seus demonstrativos, sendo esses resultados condizentes com os achados de Ettredge et al. (2010). 
A fim de analisar a relação entre a republicação das demonstrações contábeis, o gerenciamento de resultados e as variáveis de controle, procedeu-se à análise de correlação. Frisa-se, ainda, que a análise de correlação auxilia na identificação de multicolinearidade, considerando que correlações moderadas ou fortes, ou seja, com coeficiente acima de 0,8 podem indicar multicolinearidade entre as variáveis independentes. Ressalta-se que se procedeu com a verificação da multicolinearidade pelo Fator de Inflação de Variância (FIV), cujos valores foram abaixo de 5 , indicando ausência desse problema de multicolinearidade.

A Tabela 2 apresenta o resultado da análise de correlação:

Tabela 2

Análise de Correlação de Pearson

\begin{tabular}{|c|c|c|c|c|c|c|c|c|}
\hline & $(1)$ & $(2)$ & (3) & $(4)$ & (5) & (6) & $(7)$ & (8) \\
\hline REPUB & 1 & & & & & & & \\
\hline ADACC & $-0,019$ & 1 & & & & & & \\
\hline REAL & $0,073^{(* *)}$ & $-0,085^{(* * *)}$ & 1 & & & & & \\
\hline TAM & $0,058^{(* *)}$ & $-0,233^{(* * *)}$ & $-0,034$ & 1 & & & & \\
\hline REN & $-0,006$ & 0,002 & $-0,059^{(* *)}$ & 0,028 & 1 & & & \\
\hline END & $-0,007$ & $0,211^{(* * *)}$ & 0,031 & $-0,21^{(* * *)}$ & 0,008 & 1 & & \\
\hline CRES & 0,034 & $0,189^{(* * *)}$ & $-0,067^{(* *)}$ & $0,080^{(* * *)}$ & 0,086 & $-0,05^{(* *)}$ & 1 & \\
\hline MTB & 0,004 & 0,02 & $-0,013$ & $-0,105$ & $-0,404^{(* * *)}$ & $-0,014$ & $-0,040$ & 1 \\
\hline
\end{tabular}

Nota. $\left({ }^{*}\right),\left({ }^{* *}\right),\left({ }^{* * *}\right)=$ significância aos níveis de $10 \%, 5 \%$ e $1 \%$, respectivamente.

Conforme a Tabela 2, observa-se uma correlação significante com coeficiente negativo entre a manipulação por accruals (ADACC) e a manipulação por atividades operacionais (REAL), assim como no estudo de Zang (2011), que indica que há uma relação inversa entre a manipulação por accruals (ADACC) e a manipulação por atividades operacionais (REAL).

As variáveis que apresentam nível significante de correlação com o gerenciamento de resultados são o tamanho (TAM), a rentabilidade (REN), o endividamento (END) e o crescimento (CRES), destacando-se que o tamanho (TAM) e o endividamento (END) apresentaram correlação significante apenas para a manipulação por accruals discricionários, enquanto a rentabilidade (REN) foi significante, com coeficiente negativo, apenas com gerenciamento de resultados por manipulação das atividades operacionais (REAL).

Para a manipulação por accruals discricionários (ADACC) observa-se correlação inversa com o tamanho (TAM) das empresas, e relação direta com o endividamento (END) e crescimento (CRES) das empresas. Entre as associações expostas, apenas a inter-relação com o tamanho (TAM) da empresa diverge dos preceitos de Dechow, Ge, e Schrand (2010). Cabe destacar que Dechow et al. (2010) versam que os resultados da relação entre o tamanho da empresa e a qualidade da informação contábil é inconsistente, podendo ter efeito positivo ou negativo. Já para a manipulação das atividades operacionais (REAL) (manipulação de 
vendas, redução das despesas discricionárias e superprodução), a correlação é positiva em relação ao tamanho (TAM) das empresas e se mostra negativa em relação à rentabilidade (REN). Essas correlações corroboram os achados de Ge e Kim (2014).

Para aplicação da regressão logística, verificou-se a validade do modelo por meio do Teste de Hosmer e Lemeshow, que revelou um Qui-quadrado de 6,47, com significância de 0,595 (sig. > 0,05), indicando que os valores previstos não são significativamente diferentes dos observados, confirmando-se, assim, a regressão para estimar a probabilidade de ocorrência da republicação em razão das variáveis independentes consideradas no modelo.

Destaca-se ainda que, por meio da curva ROC, foi observada a capacidade de predição do modelo, mostrando-se aceitável para a regressão logística proposta, na qual o indicador da área sob a curva ROC para o modelo resultou superior a 0,5.

A Tabela 3 apresenta os resultados da análise de regressão logística para verificar a relação entre o gerenciamento de resultados e a probabilidade de as empresas praticarem a republicação de demonstrações.

Tabela 3

Regressão Logística com erros robustos e efeitos aleatórios

\begin{tabular}{|c|c|c|c|c|}
\hline Variável & & Coeficiente & $\mathrm{p}$-value & \\
\hline \multirow[t]{2}{*}{ Accruals discricionários } & ADACC & 0,008 & 0,991 & \\
\hline & & $(0,692)$ & & \\
\hline \multirow[t]{2}{*}{ Manipulação de atividades operacionais } & REAL & 0,838 & 0,008 & $\left({ }^{* * *}\right)$ \\
\hline & & $(0,317)$ & & \\
\hline \multirow[t]{2}{*}{ Tamanho } & TAM & 0,103 & 0,053 & $\left({ }^{*}\right)$ \\
\hline & & $(0,053)$ & & \\
\hline \multirow[t]{2}{*}{ Rentabilidade } & REN & $-0,023$ & 0,836 & \\
\hline & & $(0,112)$ & & \\
\hline \multirow[t]{2}{*}{ Endividamento } & END & $-0,023$ & 0,851 & \\
\hline & & $(0,124)$ & & \\
\hline \multirow[t]{2}{*}{ Crescimento de vendas } & CRES & 0,414 & 0,091 & $(*)$ \\
\hline & & $(0,245)$ & & \\
\hline \multirow[t]{2}{*}{ Market-to-book } & MTB & $-0,001$ & 0,628 & \\
\hline & & $(0,003)$ & & \\
\hline \multirow[t]{2}{*}{ Intercepto } & & $-2,011$ & 0,000 & $\left({ }^{* * *}\right)$ \\
\hline & & $(0,462)$ & & \\
\hline Observações & & 814 & & \\
\hline Empresas & & 154 & & \\
\hline Wald Qui ${ }^{2}$ & & 16,14 & 0,0239 & $(* *)$ \\
\hline
\end{tabular}

Nota. $\left({ }^{*}\right),\left({ }^{* *}\right),\left({ }^{* * *}\right)$ significância aos níveis de $10 \%, 5 \%$ e 1\%, respectivamente. Em parênteses estão os erros-padrão robustos.

Por meio do teste Wald Qui ${ }^{2}$, identifica-se que pelo menos uma das variáveis no modelo explica a propensão das empresas a republicarem seus demonstrativos contábeis. Entre 
as variáveis, o gerenciamento de resultados por manipulação das atividades operacionais (REAL), além do tamanho da empresa e do crescimento de vendas explicam a propensão à republicação.

Esses resultados aqui encontrados corroboram os estudos de Baptista (2008), Ettredge et al. (2010), Linn e Diehl (2005) e Richardson et al. (2002), revelando, desse modo, que os gestores podem adotar políticas contábeis agressivas e que as informações contidas nos accruals discricionários podem ser relevantes para antecipar o gerenciamento de resultados naquelas empresas que republicaram suas demonstrações financeiras (Richardson et al., 2002). Também coadunam com Marques et al. (2017), ao identificar que as empresas maiores e de maior crescimento nas vendas tendem a republicar mais as demonstrações contábeis.

Esse resultado não rejeita a hipótese de estudo, uma vez que era esperada uma relação positiva, pois, segundo Dechow et al. (2010), gerenciamento de resultados e republicação de demonstrações impactam a qualidade da informação contábil. Portanto, essas práticas influenciam o comportamento do mercado, criando uma reação negativa pelos usuários da informação, e, consequentemente, uma potencial queda nos preços das ações (Richardson et al., 2002), especialmente quando as republicações envolvem fraudes, afetam mais contas contábeis e alteram as principais receitas (Palmrose et al., 2004), fazendo com que as empresas percam credibilidade (Chen et al., 2014). Apesar disso, no Brasil, Helou e Pereira (2010) não encontraram reação positiva nem negativa do mercado às republicações de informações contábeis.

\section{CONCLUSÃO}

Os usuários das demonstrações contábeis aguardam a divulgação oportuna e de qualidade das informações que representam a realidade econômica, financeira e patrimonial da empresa, para que possam subsidiar o seu processo decisório. É importante que a informação seja correta, sem a ocorrência de vieses informacionais que possam interferir inadequadamente nas decisões desse segmento. No entanto, se houver indícios de erros, falhas, fraudes e/ou gerenciamento de resultados na elaboração das demonstrações contábeis, torna-se necessária sua republicação. Nesse contexto, o presente estudo investigou se as práticas de gerenciamento de resultados nas companhias listadas na B3 relacionam-se com a republicação das suas demonstrações contábeis.

Para tanto, foi realizada uma pesquisa descritiva e documental, com dados de 154 empresas listadas na B3, perfazendo um total de 814 observações, compreendendo o período de 2011 a 2017. Foram utilizadas as técnicas de análise de conteúdo, estatística descritiva, análise de correlação e regressão logística, por meio das quais foi possível verificar que há uma relação positiva entre a republicação de demonstrações contábeis e a prática de 
gerenciamento de resultados por manipulação das atividades operacionais, não se rejeitando, assim, a hipótese de pesquisa.

Os achados deste estudo corroboram a literatura (Ettredge et al., 2010; Linn \& Diehl, 2005; Marques et al., 2017; Richardson et al., 2002) e confirmam que ambos os construtos investigados-gerenciamento de resultados e republicação de demonstrações contábeis-estão intrinsecamente relacionados com a qualidade da informação contábil (Dechow et al., 2010). Dessa forma, observou-se que as empresas que mais se engajam em práticas contábeis agressivas, ou seja, em práticas de gerenciamento de resultados por manipulação das atividades operacionais, possuem maior propensão à republicação de seus demonstrativos. Além disso, identificou-se que as empresas maiores e de maior crescimento nas vendas tendem a republicar mais as demonstrações contábeis.

Cabe destacar que o maior número de republicação de demonstrações contábeis ocorreu nos três primeiros anos de análise, coincidindo com os anos iniciais de adoção obrigatória das IFRS no Brasil, corroborando o estudo de Marques et al. (2017).

Esse resultado gera implicações práticas, pois sinaliza de forma indireta para os investidores ou quaisquer outros stakeholders que as empresas com maior número de republicação de demonstrações contábeis se engajam mais em práticas contábeis agressivas, como manipulação de atividades operacionais. Assim, os investidores podem repensar seus investimentos e tomar decisões mais precisas.

Entre as principais limitações da presente pesquisa, destacam-se a amostra e o tipo de republicação das demonstrações contábeis apresentadas pelas empresas. Quanto à amostra, considerando-se o cenário brasileiro, tem-se um reduzido número de observações relacionadas às republicações. A maioria das empresas brasileiras republicam de forma voluntária, sem alteração de valores ou resultados contábeis, impossibilitando outros tipos de análise. Dessa forma, para pesquisas futuras, sugere-se ampliar a análise para uma amostra global. Além disso, na literatura nacional ainda há poucos estudos que investigam a republicação. Assim, sugere-se verificar as consequências da republicação das demonstrações contábeis, especialmente quanto à reação de mercado ou seu value relevance.

\section{REFERENNCIAS}

Abad, D., Cutillas-Gomariz, M. F., Sánchez-Ballesta, J. P., \& Yagüe, J. (2018). Real earnings management and information asymmetry in the equity market. European Accounting Review, 27(2), 209-235.

Ahmed, K., \& Goodwin, J. (2007). An empirical investigation of earnings restatements by Australian firms. Accounting and Finance, 47(1), 1-22. 
Alali, F., \& Wang, S. (2017). Characteristics of financial restatements and frauds: An analysis of corporate reporting quality from 2000-2014. The CPA Journal, 87(11), 32-41.

Albring, S., Huang, S., Pereira, R., \& Xu, X. (2013). The effects of accounting restatement on firm growth. Journal of Accounting and Public Policy, 32(5), 357-376.

Baptista, E. (2008). Solicitação de refazimento/republicação: Prox de gerenciamento? Anais do Encontro da Associação Nacional de Pós-Graduação e Pesquisa em Administração, Rio de Janeiro, 32.

Barros M. E., Menezes, J. T., Colauto, R. D., \& Teodoro, J. D. (2014). Gerenciamento de resultados e alavancagem financeira em empresas brasileiras de capital aberto. Contabilidade, Gestão e Governança, 17(1), 35-55.

Bills, K., Swanquist, Q., Whited, R. (2016). Growing pains: Audit quality and office growth. Contemporary Accounting Research, 33(1), 288-313.

Bischoff, J., Finley, J., \& Leblanc, D. (2008). Financial statement restatements: Cause and effect. Tennessee CPA Journal, 5-7.

Chen, K., Elder, R., \& Hung, S. (2014). Do post-restatement firms care about financial credibility? Evidence from the pre- and post-SOX eras. Journal of Accounting Public Policy, $33(2), 107-126$.

Chen, S., Goo, Y.-J. J., \& Shen, Z.-D. (2014). A Hybrid Approach of Stepwise Regression, Logistic Regression, Support Vector Machine, and Decision Tree for Forecasting Fraudulent Financial Statements. The Scientific World Journal, 1-9.

Chiudini, V., Cunha, P. R. da, \& Marques, L. (2018). Relação entre a republicação das demonstrações contábeis e o Audit Delay. Revista Catarinense da Ciência Contábil, 17(51), 89-107.

Cohen, D. A., Dey, A., \& Lys, T. Z. (2008). Real and accrual-based earnings management in the pre- and post-Sarbanes-Oxley periods. The Accounting Review, 83(3), 757-787.

Collins, D., Masli, A., Reitenga, A. L., \& Sanchez, J. M. (2009). Earnings Restatements, the Sarbanes-Oxley Act, and the Disciplining of Chief Financial Officers. Journal of Accounting, Auditing \& Finance, 24(1), 1-34.

Consoni, S., Colauto, R. D., \& Lima, G. A. S. F. (2017). A divulgação voluntária e o gerenciamento de resultados contábeis: Evidências no mercado de capitais brasileiro. Revista Contabilidade \& Finanças, 28(74), 249-263. 
Costa, F. C., Filho, De Luca, M. M. M., Góis, A. D, \& Lima, G. A. S. F. (2018). Gerenciamento de resultados: $O$ impacto do ciclo de vida organizacional e da adoção das IFRS. Anais dos Seminários de Administração, SemeAd, São Paulo, 21.

Cunha, P. R., Fernandes, L., \& Magro, C. (2017) Influência do refazimento das demonstrações contábeis no gerenciamento de resultados das empresas listadas na BM\&FBovespa. RACE, Revista de Administração, Contabilidade e Economia, 16(1), 95-107.

Dantas, J., Chaves, S. M., Silva, M., \& Carvalho, R. (2011). Determinações de refazimento/ republicação de demonstrações financeiras pelas CVM: $O$ papel dos auditores independentes. Revista Universo Contábil, 7(2), 45-64.

Dechow, P. M., \& Dichev, I. D. (2002). The quality of accruals and earnings: The role of accrual estimation errors. The Accounting Review, 77(1), 35-59.

Dechow, P. M., Ge, W., \& Schrand, C. (2010). Understanding earnings quality: A review of the proxies, their determinants and their consequences. Journal of Accounting and Economics, 50(2-3), 344-401.

Dechow, P. M., Sloan, R. G., \& Sweeny, A. P. (1995). Detecting earnings management. The Accounting Review, 70(2), 193-225.

Elayan, F., Li, J., \& Meyer, T. (2008). Accounting irregularities, management compensation structure and information asymmetry. Accounting and Finance, 48(5), 741-760.

Ettredge, M., Scholz, S., Smith, K., \& Sun, L. (2010). How do restatements begin? Evidence of earnings management preceding restated financial reports. Journal of Business $\mathrm{Fi}$ nance \& Accounting, 37(3), 332-355.

Gao, J., Gao, B., \& Wang, X. (2017). Trade-off between real activities earnings management and accrual-based manipulation-evidence from China. Journal of International Accounting, Auditing and Taxation, 29, 66-80.

Ge, W., \& Kim, J. B. (2014). Real earnings management and the cost of new corporate bonds. Journal of Business Research, 67(4), 641-647.

Góis, A. D., \& Soares, S. V. (2019). O Efeito da reputação corporativa segundo a transparência contábil no gerenciamento de resultados de empresas listadas na B3. Revista de Educação e Pesquisa em Contabilidade (REPeC), 13(2), 209-234.

Grecco, M. C. P. (2013). The Effect of Brazilian convergence to IFRS on earnings managment by listed Brazilian nonfinancial companies. Brazilian Business Review, 10(4), 110-132. 
Healy, P. M., \& Wahlen, J. M. (1999). A review of the earnings management literature and its implications for standard setting. Accounting Horizons, 13(4), 365-383.

Healy, P. M., Hutton, A., \& Palepu, K. (1999). Stock Performance and Intermediation Changes Surrounding Sustained Increases in Disclosure. Contemporary Accounting Research, $16(3), 485-520$.

He, L., \& Chiang, H. (2013). Market reaction to financial statement restatement: A study on the information and insurance role of auditors. Advances in Management and Applied Economics, 3(4), 37-50.

Helou, F., Netto, \& Pereira, C. C. (2010). Impacto da republicação de demonstrações financeiras no preço das ações de empresas brasileiras. Revista Contemporânea de Contabilidade, 7(14), 29.

Jensen, M. C., \& Meckling, W. H. (1976). Theory of the firm: Managerial behavior, agency costs and ownership structure. Journal of Financial Economics, 3(4), 305-360.

Joia, R. M., \& Nakao, S. H. (2014). Adoção de IFRS e gerenciamento de resultado nas empresas brasileiras de capital aberto. Revista de Educação e Pesquisa em Contabilidade $(R E P e C), 8(1), 22-38$.

Linhares, F., Costa, F., \& Beiruth, A. (2018). Earnings management and investment efficiency. Review of Business Management, 20(2), 295-310.

Linn, E., \& Diehl, K. (2005). Financial restatements: Causes, consequences, and corrections. Strategic Finance, 87(3), 34-39.

Lin, P., Lee, S., Chen, X., \& Yur-Austin, J. (2015). Highlights of financial restatements from 2000 through 2011. Management Accounting Quarterly, 17(1), 1-12.

Liu, X., \& Yu, H.C. (2018). How do companies react to restatements? Evidence from audit committee compensation. Asia-Pacific Journal of Accounting \& Economics, 25(5), 546585.

Marçal, R. R., \& Macedo, M. A. da S. (2019). Análise da persistência do lucro diante dos accruals discricionários: Um estudo com base no impacto da adoção das IFRS. ContextusRevista Contemporânea de Economia e Gestão, 17(2), 129-159.

Mao, Y. (2018). Financial Restatement Research Literature Review. Modern Economy, 9(12), 2092-2103. 
Marques, V., Aires, D., Cerqueira, N., Silva, L., \& Amaral, H. (2016). Dinâmica das republicações das demonstrações contábeis no período de 1997-2012. Revista Contabilidade, Gestão e Governança, 19(3), 440-464.

Marques, V., Amaral, H., Souza, A., Santos, K., \& Belo, P. (2017). Determinantes das republicações no mercado brasileiro: Uma análise a partir dos incentivos ao gerenciamento de resultados. Revista de Educação e Pesquisa em Contabilidade (REPeC), 11(2), 191-213.

Mcvay, S. E. (2006). Earnings management using classification shifting: An examination of core earnings and special items. The Accounting Review, 81(3), 501-531.

Mortazavi, S.A., \& Salehi, A. K. (2017). Investigating the Relationship between Earnings Management and Cash Management with the Restated Financial Statements of Companies Listed in Tehran Stock Exchange. International Journal of Economic Perspectives, $11(1), 1055-1060$.

Mulford, C. W., \& Comiskey, E. E. (2002). The financial numbers game: Detecting creative accounting practices. New York: John Willey Trade.

Murcia, F. D. R., Borba, J. A., \& Amaral, N. (2005). Financial Report Restatements: Evidences from the Brazilian Financial Market. Anais do CLADEA, Santiago, 40.

Murcia, F. D. R., \& Carvalho, L. N. (2007). Conjecturas acerca do gerenciamento de lucros, republicação das demonstrações contábeis e fraude contábil. Contabilidade Vista \& Revista, 18(4), 61-82.

Murcia, F. D. R., \& Wuerges, A. (2011). Escolhas contábeis no mercado brasileiro: divulgação voluntária de informações versus gerenciamento de resultados. Revista Universo Contábil, 7(2), 28-44.

Oliveira, V. \& Lemes, S. (2011). Nível de convergência dos princípios contábeis brasileiros e norte-americanos às normas do IASB: Uma contribuição para a adoção das IFRS por empresas brasileiras. Revista Contabilidade \& Finanças, 22(56), 155-173.

Palmrose, Z., Richardson, V. J., \& Scholz, S. (2004). Determinants of market reactions to restatement announcements. Journal of Accounting and Economics, 37(1), 59-89.

Piccoli, P. G. R., Souza, A., \& Silva, W. V. (2014). As práticas de governança corporativa diminuem o gerenciamento de resultados? Evidências a partir da aversão na divulgação de prejuízos e de queda nos lucros. Revista Contemporânea de Contabilidade, 11(22), 141-162. 
Rahmanian, H., Rahmani, H., \& Jafari, S. M. (2016). Relationship between restatement of financial statements and information asymmetry. International Journal of Humanities and Cultural Studies, 3(1), 1721-1732.

Richardson, S., Tuna, I., \& Wu, M. (2002). Predicting earnings management: The case of earnings restatements. Retrieved from http://ssrn.com/abstrat $=338681$

Roychowdhury, S. (2006). Earnings management through real activities manipulation and corporate governance mechanism model. Journal of Accounting and Economics, 42(3), 335-370.

Sampieri, R. H., Collado, C. F., \& Lúcio, P. B. (2013). Metodologia de pesquisa. (3a ed.). São Paulo: McGraw Hill.

Scott, W. R. (2003). Financial Accounting Theory. (3 $3^{a}$ ed.). Toronto: Prentice Hall.

Segal, D., Callen, J., \& Livnat, J. (2006). Accounting restatements: Are they always bad news for investors? Journal of Investing, 15(3), 57-68.

Silva, A. H. C., Silva, C. E. V., Sanconvschi, M., \& Borba, J. A. (2018). Analysis of discontinued operations in Brazil after IFRS 5 adoption. Contextus-Revista Contemporânea de economia e gestão, 16(3), 8-39.

Soares, C. R., Motoki, F. Y. S., \& Monte-Mor, D. S. (2018). IFRS e probabilidade de republicação: Um estudo das empresas brasileiras listadas na Bovespa. Revista Catarinense da Ciência Contábil, 17(52), 70-83.

Souza, W. R. S., Peters, M., Silva, A. F. da, \& Antunes, M. T. P. (2018). Vinte e um anos sem correção monetária no Brasil: Impactos na comparabilidade da informação contábil em empresas siderúrgicas e metalúrgicas. Revista Contabilidade \& Finanças, 29(78), 355374.

Teixeira, S. A., Politelo, L., \& Klann, R. C. (2013). Fatores relacionados ao refazimento das demonstrações contábeis das companhias brasileiras de capital aberto. Anais do Encontro Nacional de Cursos de Graduação em Administração, Florianópolis, 24.

Teoh, S. H., Welch, I., \& Wong, T. J. (1998). Earnings management and the long run market performance of initial public offerings. The Journal of Finance, 3(6), 1935-1974.

Wiedman, C., \& Hendricks, K. (2013). Firm accrual quality following restatements: A signaling view. Journal of Business Finance \& Accounting, 40(9-10), 1095-1125. 
Zang, A. Y. (2011). Evidence on the trade-off between real activities manipulation and accrual-based earnings management. The Accounting Review, 87(2), 675-703.

Como citar este artigo:

\section{ABNT}

DE LUCA, Márcia Martins Mendes et al. Gerenciamento de resultados e republicação de demonstrações contábeis em empresas listadas na B3. RACE, Revista de Administração, Contabilidade e Economia, Joaçaba: Editora Unoesc, v. 19, n. 2, p. 249-272, maio/ago. 2020. Disponível em: http://editora.unoesc.edu.br/index.php/race. Acesso em: dia/mês/ano.

\section{APA}

De Luca, M. M. M., Viana, A. O. B., Sousa, K. D. F. de, Cavalcante, D. S., \& Cardoso, V. I. da C. (2020). Gerenciamento de resultados e republicação de demonstrações contábeis em empresas listadas na B3. RACE, Revista de Administração, Contabilidade e Economia, 19(2), 249-272. Recuperado de http://editora.unoesc.edu.br/index.php/race 